Geophysical Research Abstracts,

Vol. 10, EGU2008-A-04239, 2008

SRef-ID: $1607-7962 /$ gra/EGU2008-A-04239

EGU General Assembly 2008

(C) Author(s) 2008

\title{
Temporal variability of gas seeps offshore New Zealand: Multi-frequency geoacoustic imaging of the Wairarapa area, Hikurangi margin
}

Ingo Klaucke (1), Wilhelm Weinrebe (1), Jörg Petersen (1), Jens Greinert (2), Andrew T. Jones (3)

(1) Leibniz Institute of Marine Sciences, IfM-GEOMAR, Kiel, Germany

(iklaucke_at_ifm-geomar.de), (2) Renard Centre of Marine Geology, Ghent University, Belgium, (3) Geoscience Australia, Petroleum and Marine Division, Canberra, Australia

Cold seeps of the Wairarapa area situated around 1000 metres water depth on the Hikurangi margin offshore New Zealand's North Island have been investigated using multibeam bathymetry, 75 and $410 \mathrm{kHz}$ sidescan sonar imagery as well as 2-8 kHz Chirp sediment echosounder data. Towed video camera observations allowed groundtruthing the various geoacoustic data. At least eight different seep locations displaying various degrees of seep activity have been identified in the study area which consists of an elongated, northward-widening ridge that is part of the Hikurangi margin accretionary complex and well separated from direct terrigenous input by margin channels surrounding the ridge. The geoacoustic signature of individual cold-seep sites range from smooth areas with slightly elevated backscatter intesity resulting from high gas content or the presence of near-surface gas hydrates to rough areas with widespread patches of carbonates at the seafloor. Two cold seeps also show indications for active gas emissions in form of acoustic plumes in the water column. Repeated sidescan sonar imagery of the plumes indicates they are highly variable in intensity and directivity in the water column reflecting a likely control of gas emission by tides and currents. Although gas emission appears strongly focused in the Wairarapa area the actual extent of the cold seep structures are slightly wider in the subsurface as shown by sediment echosounder profiles. On a larger scale, however, fluid seepage at the Wairarapa area is still highly focused. 